Original Article

\title{
ROLE OF MICHELIA CHAMPACA IN MEMORY ENHANCEMENT AND ACUTE NOISE STRESSED MALE WISTAR ALBINO RATS
}

\author{
MALATHI S., VIDYASHREE, RAVINDRAN RAJAN* \\ Department of Physiology, Dr. ALM PG Institute of Basic Medical Sciences, University of Madras, Chennai 600113, Tamil Nadu, India \\ Email: dr.ravindranrajan87@gmail.com
}

Received: 15 Sep 2017 Revised and Accepted: 03 Jan 2018

\begin{abstract}
Objective: To identify the memory enhancing role of Michelia champaca in acute noise stressed animals.

Methods: Male Wistar albino rats were used in this study. Animals were exposed to noise for $4 \mathrm{~h}$ before testing for memory. Thereafter, the plasma corticosterone level and acetylcholinesterase activity were estimated in the discrete regions of the brain, and the memory related behavior were assessed by eight arm radial maze.

Results: Our results showed that Michelia champaca enhances the memory activity and decreases the corticosterone concentrations in acute noise stress animals treated with M. champaca. Moreover, it also decreased brain acetylcholinesterase activity when compared with the acute stress group $(\mathrm{p}<0.05)$. Furthermore, behavioral tests indicate that working memory, is enhanced by acute stress and decreases the error levels in all the parameters studied in the behavior aspects when compared to control animals.
\end{abstract}

Conclusion: These findings suggest that Michelia champaca enhances the memory in albino rats and might be useful therapeutically for cognitive related dysfunctions. This could be due to the presence of memory boosting compounds and its antistressor and anti-acetylcholinesterase activity, thereby reduces the levels of serum corticosterone and inhibition of cholinesterase enzyme significantly.

Keywords: Michelia champaca, Memory, Corticosterone, Acute noise stress, Acetylcholinesterase activity, Eight-arm radial maze

(C) 2018 The Authors. Published by Innovare Academic Sciences Pvt Ltd. This is an open access article under the CC BY license (http://creativecommons.org/licenses/by/4.0/) DOI: http://dx.doi.org/10.22159/ijpps.2018v10i2.22605

\section{INTRODUCTION}

In response to stress, the brain recruits many neuronal circuits to adapt to the demand, leading to the activation of hypothalamicpituitary-adrenocortical [HPA] axis, and the production of adrenal corticosterone, the major stress hormone [1]. Appropriate regulation of the HPA axis is critical for health and survival, and several limbic brain structures, including the hippocampus, are involved in the integration of HPA hormonal responses [2]. Corticosterone exerts its cellular effects by acting on mineralocorticoid receptors and glucocorticoid receptors. Importantly, stress hormones have both protective and damaging effects on the body [3]. In case of acute stress, they are essential for adaptation and maintenance of homeostasis, while in response to chronic and repeated stress, they can produce wear and tear on the body [4]. Consistently, behavioral studies have found that moderate acute stress facilitates classical conditioning and associative learning $[5,6]$ in contrast to the chronic stress-induced deficits in spatial and contextual memory performance and attentional control $[7,8]$.

Several, researches in neuroscience and experimental psychology have probed the effects of stress on learning and memory. While abundant work has reconnoitered the effects of acute and chronic stress on memory encoding and consolidation, the extent to which acute stress specifically influences retrieval processes in humans is less well understood. Many studies have observed how stress influences learning and memory aptitudes $[9,10]$. On the other hand, it's generally accepted that stressful events are very well remembered. Studies with animals, using pharmacological and genetic tools, have indeed shown that stress facilitates, and might even be indispensable for, good learning and memory performance [11]. Poor memory, lower retention, and slow recall are common problems in today's stressful and competitive world. In India, the rate of Alzheimer's disease and other dementias is increasing every year and it is expected to increase two-fold by 2030 and three-fold by 2050. Management of cognitive disorders has been challenging since no potential drug is available with proved efficacy.
Moreover, there are few reports available to show the changes in the activity of corticosterone and acetylcholinesterase [AchE] in discrete regions of the brain in animals induced by the various duration of stress and their effect on memory. Furthermore, the reports regarding the effects of Michelia champaca on acute noise stress on the neurological system are very scanty. The allopathic system of medicine is yet to provide a satisfactory remedy for the alleviation of human suffering. The drugs of plant origin are gaining increasing popularity and are being investigated for remedies of several disorders. M. champaca is a folk-medicinal plant, well known for its antioxidant and antidiabetic property, [12] it also has other numerous properties such as analgesic, anti-inflammatory, and [13] anticancer activities [14]. These unique effects are due to the presence of compounds like phenols, saponins, tannins, amino acids, flavonoids, terpenoids, and catecholamines, [15] involved in biological manipulations and activities. However, the perusal of literature reveals that, so far, no attempt was made to study the role of $M$. champaca in relation to acute noise and central cholinergic system in the whole brain or in discrete areas of the brain in animal models has not been studied much. Hence this is the first study planned to assess the effects of acute noise stress and role of $M$. champaca on learning and memory functions. Further, it aimed at studying the concentration of corticosterone in the serum and acetylcholinesterase level in discrete brain regions namely pre-frontal cortex, corpus striatum, hippocampus, and hypothalamus. This study, helps to understand the between acute stress and memory.

\section{MATERIALS AND METHODS}

Chemicals

Chemicals used were of analytical grade and obtained from Sisco Research Laboratory, Mumbai, India.

Experimental groups

The experiments were carried out by using healthy adult male Wistar rats (180-200 g). The study was initiated with a proper 
approval by the Institute's Animal Ethical Committee (IAEC No.: $01 / 23 / 2014$ ). Animals were divided into four groups (control, control treated with $M$. champaca, acute noise exposed and acute noise stressed rats treated with M. champaca. All the rats used in this study were maintained at a constant temperature with a $12 \mathrm{~h}$ light: $12 \mathrm{~h}$ dark cycle and allowed free access to food and water. All groups were handled similarly.

\section{Noise stress procedure}

Broadband (white) noise was produced by a white noise generator $(0-26 \mathrm{KHZ})$ and amplified by an amplifier $(40 \mathrm{~W})$ connected to two loud speakers $(15 \mathrm{~W})$ located at $30 \mathrm{~cm}$ above the animal cage. The intensity of the sound was measured by a sound level meter (Quest electronics cygnet systems D2023, serial No F02199, India) and maintained at 100dBA intensity. Animals were exposed to noise for $4 \mathrm{~h}$. To avoid the influence of handling stress, control rats were kept under the same set up during the corresponding period without exposing them to noise [16].

\section{Preparation of methanol extract of $M$. champaca}

M. champaca was collected from the local area and confirmed by the botanist and a sample was deposited in a herbarium (Reg. No.: NIS/MB/94/2013). M. champaca dry flowers of 10 grams were soaked in $100 \mathrm{ml}$ (twice, i.e., $2 \times 100 \mathrm{ml}$ ) of methanol for 8-10 d at room temperature in dark conditions, stirring every $18 \mathrm{~h}$ using sterile rod. The final extracts were filtered using a Whatman No 1 filter paper. The filtrate was concentrated to dryness under reduced pressure at $40{ }^{\circ} \mathrm{C}$ using a rotary evaporator and stored at $4{ }^{\circ} \mathrm{C}$ for further use. An oral dose of $400 \mathrm{mg} / \mathrm{kg} /$ body weight were administered orally in this study.

\section{Assay of corticosterone}

The corticosterone assay [17] is based on the oxidation of corticosteroids with ferric iron (III) in an acidic medium and subsequent complex with ferrous iron (II) and potassium hexacyanoferrate. $0.5 \mu \mathrm{l}$ was mixed with appropriate volumes of the working solutions of corticosterone and were transferred into a series of $10 \mathrm{ml}$ volumetric flasks. $2 \mathrm{ml}$ of sulfuric acid and $2 \mathrm{ml}$ of ferric chloride was added to $0.5 \mathrm{ml}$ of potassium hexacyanoferrate (III) solution. This mixture was heated in a water bath maintained at $70{ }^{\circ} \mathrm{C} \pm 2{ }^{\circ} \mathrm{C}$ for $30 \mathrm{~min}$ with occasional shaking and diluted to the 5 $\mathrm{ml}$ mark with distilled water. The absorbance was measured at 780 $\mathrm{nm}$ against the reagent blank.

\section{Assay of acetyl cholinesterase}

The tissue was homogenized [18] (approximately $20 \mathrm{mg}$ of tissue per $\mathrm{ml}$ of phosphate buffer (PH8.0: 0.1M) in a Potter-Elvehjem Homogenizer. A $0.4 \mathrm{ml}$ aliquot of brain homogenate was added to a cuvette containing $2.6 \mathrm{ml}$ of phosphate buffer (pH8.0: 0.1M) $100 \mu \mathrm{l}$ of DTNB reagent was added to the photocell. The absorbance was measured at $412 \mathrm{~nm}$. Then $0.02 \mathrm{ml}$ of acetyl thiocholine iodide was added. Changes in the absorbance were recorded and the change in absorbance per minute was calculated and 0.1 of esterine sulphate was added to the reaction mixture to determine the nonspecific esterase activity. The difference in the rate of activity was found and the AChE activity was calculated. The enzyme activity was expressed as $\mu$ moles of AThI hydrolyzed $/ \mathrm{min} / \mathrm{g}$ tissue.

\section{Eight-arm maze}

Eight-arm radial maze is used to assess spatial learning and memory [19]. A group of animals was trained prior to the experiment and during training, food act as the reward to animals, and placed in their respective arms. Initially, animals could freely explore the maze with all arms baited with cereal. The adaptation occurs after a week, each rat was individually housed in a small cage. The adaptation and maze test were performed between 10 and $12 \mathrm{~h}$. On the $3^{\text {rd }}$ day, for each rat, a piece of cereal in only four of the eightarms were kept and were trained to locate the four food rewards. Each individual rat had its own set of four rewarded arms. The room contained several visual reference cues on the wall and only four arms (fixed for each animal). Each trial began with the placement of the animal on the central platform facing toward arm number one and ended when the rat had visited the four baited arms and the time taken was noted. Otherwise, the rats were given a maximum of after a period of $10 \mathrm{~min}$. Reference and working memory error and time taken to complete the task were analysed in all the groups.

\section{Statistical analysis}

Data were expressed as mean \pm standard deviation (SD). All the data were analyzed with the SPSS for windows statistical package (version 20.0, SPSS Institute Inc., Cary, North Carolina). The statistical significance among the four diverse groups was analyzed by using one-way ANOVA test followed by Tukey's multiple comparison tests and the significance level was fixed at $P<0.05$.

\section{RESULTS}

\section{Assessment of corticosterone level in serum}

The data were summarized in fig. 1 with mean \pm SD. The plasma corticosterone level was measured in all the distinct groups. There were significant changes observed in the corticosterone level when compared between control, acute noise stress exposed rats showed a significant increase in the corticosterone level compared to the rest of the groups control treated with $M$. champaca, and noise exposed rats which received $M$. champaca showed significant decrease $(\mathrm{p}<0.05)$ when compared to stress groups. This indicates M. champaca extract was found to be beneficial.

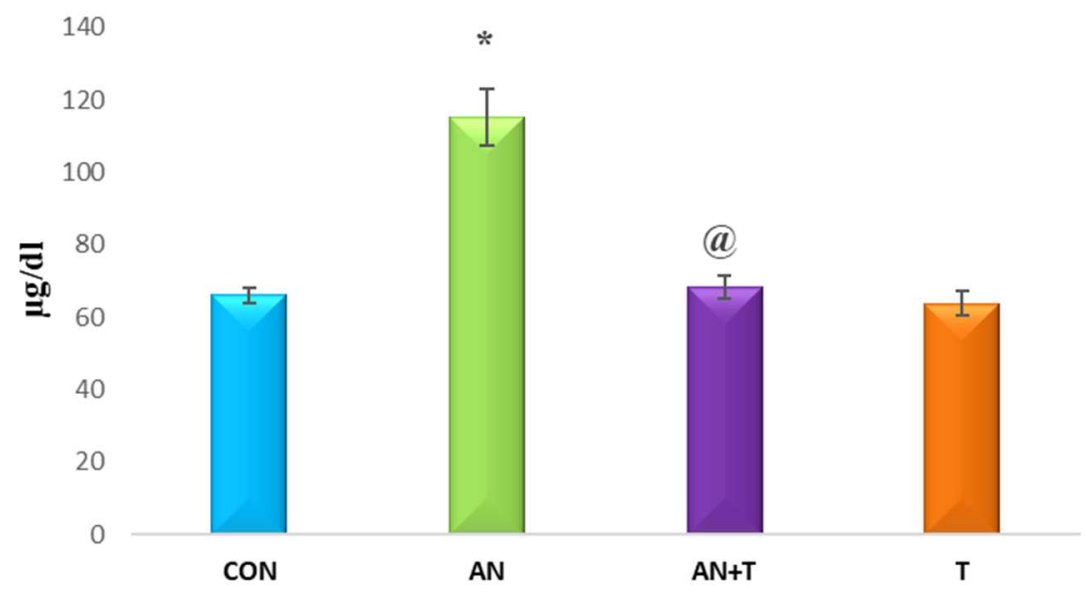

Fig. 1: Effect of Michelia champaca on plasma corticosterone in acute noise stress induced rats, values are expressed as mean $\pm \mathrm{SD}, \mathrm{N}=6$. The symbols represent statistical significance: $*$, @<P 0.05. *Compared with saline control. @Compared with acute noise stress assessment of acetylcholinesterase activity in discrete regions of brain 


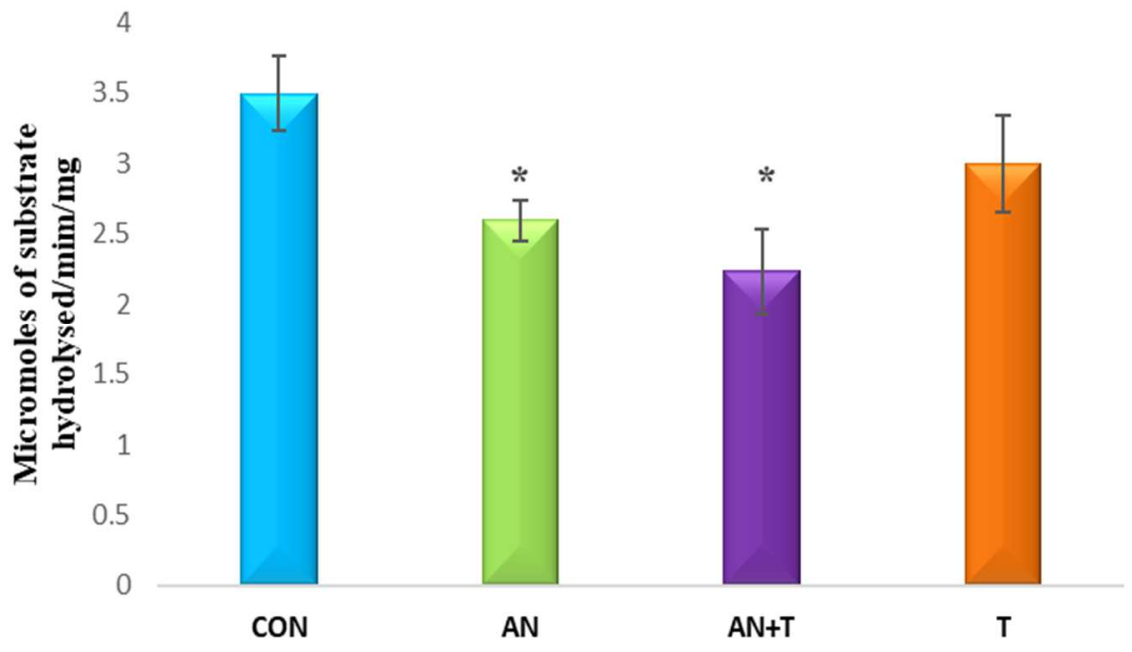

Fig. 2: Effect of Michelia champaca on acetylcholinesterase activity in prefrontal cortex, values are expressed as mean $\pm \mathrm{SD}, \mathrm{N}=6$. The symbols represent statistical significance: *, @<P 0.05. *Compared with saline control

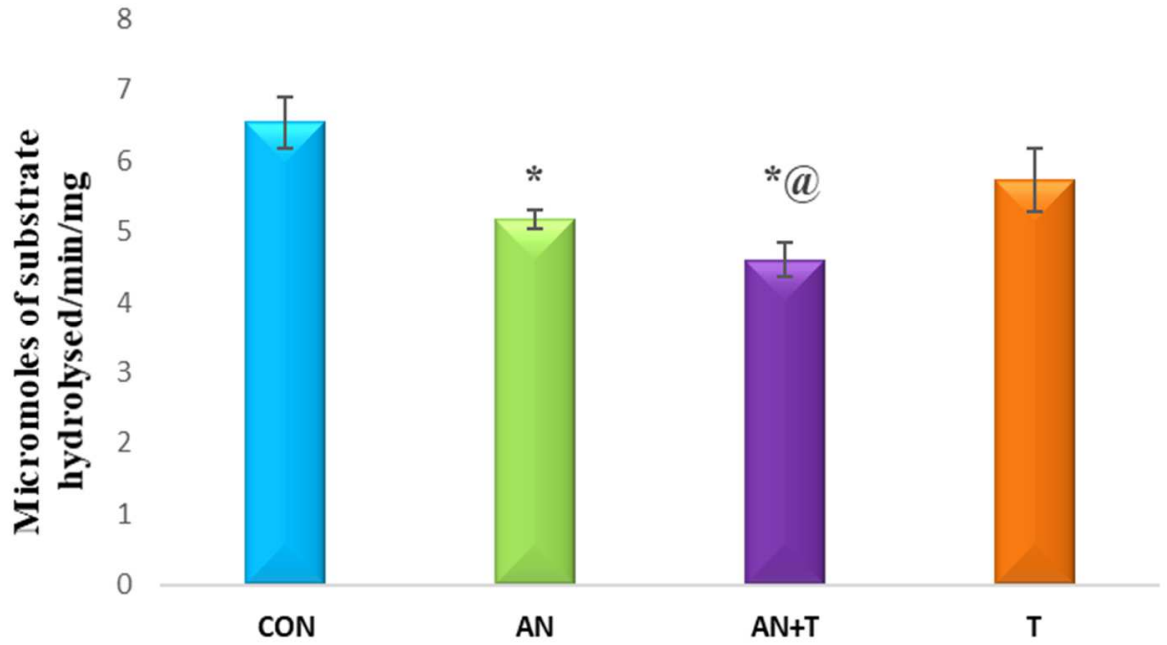

Fig. 3: Effect of Michelia champaca on acetylcholinesterase activity in corpus striatum, values are expressed as mean $\pm \mathrm{SD}, \mathrm{N}=6$. The symbols represent statistical significance: *, @<P 0.05. *Compared with saline control. @ Compared with acute noise stress

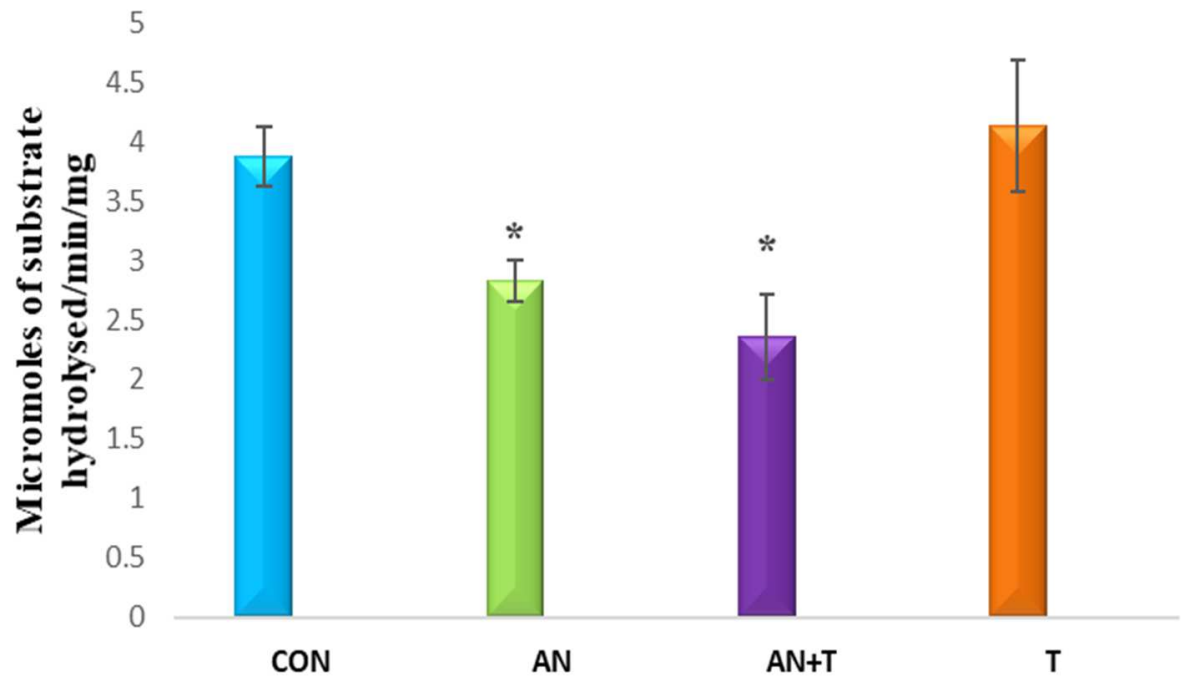

Fig. 4: Effect of Michelia champaca on acetylcholinesterase activity in hippocampus, values are expressed as mean $\pm \mathrm{SD}, \mathrm{N}=6$. The symbols represent statistical significance: *, $<$ P 0.05. *Compared with saline control 


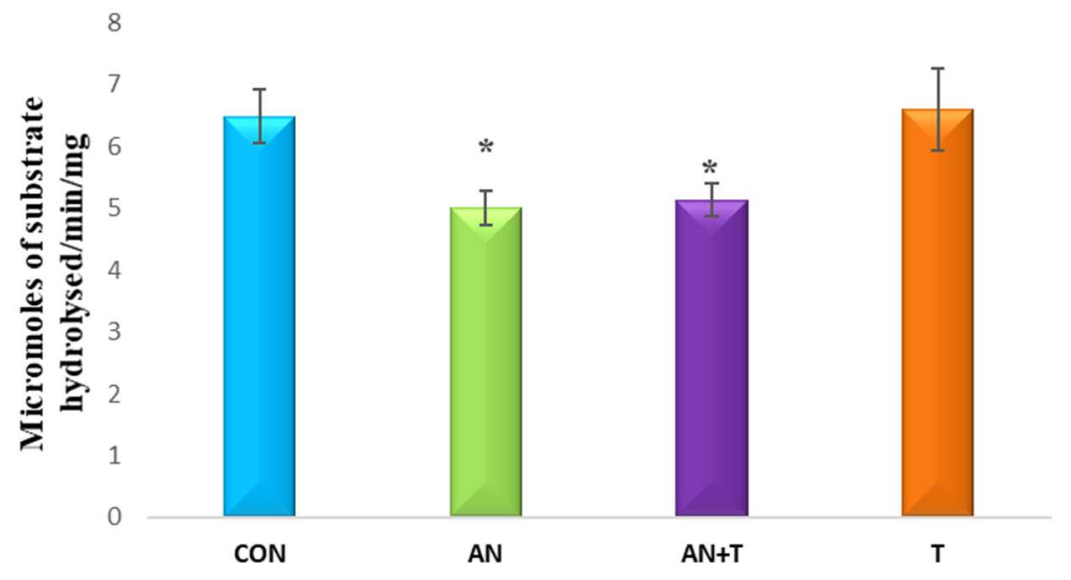

Fig. 5: Effect of Michelia champaca on acetylcholinesterase activity in hypothalamus, values are expressed as mean $\pm \mathrm{SD}, \mathrm{N}=6$. The symbols represent statistical significance: $*$, @<P 0.05. * Compared with saline control

The data from various groups are presented as bar diagram with mean \pm SD (fig. 2-5). The acetyl cholinesterase activity in acute noise stressed rats in four discrete regions showed significant decrease $(\mathrm{p}<0.05)$ when compared to other groups. Whereas acute noise stressed animal treated with $M$. champaca showed significant decrease when compared to control and treated animals.

Eight arm radial maze for memory assessment

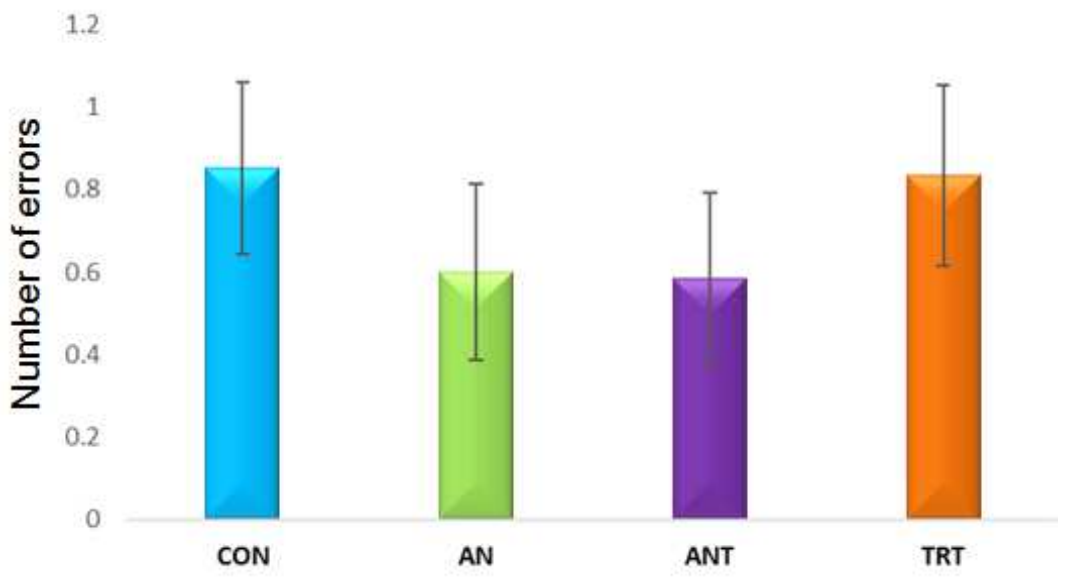

Fig. 6: Effect of Michelia champaca on reference memory error in acute noise stress induced animals, values are expressed as mean \pm SD, $\mathrm{N}=6$

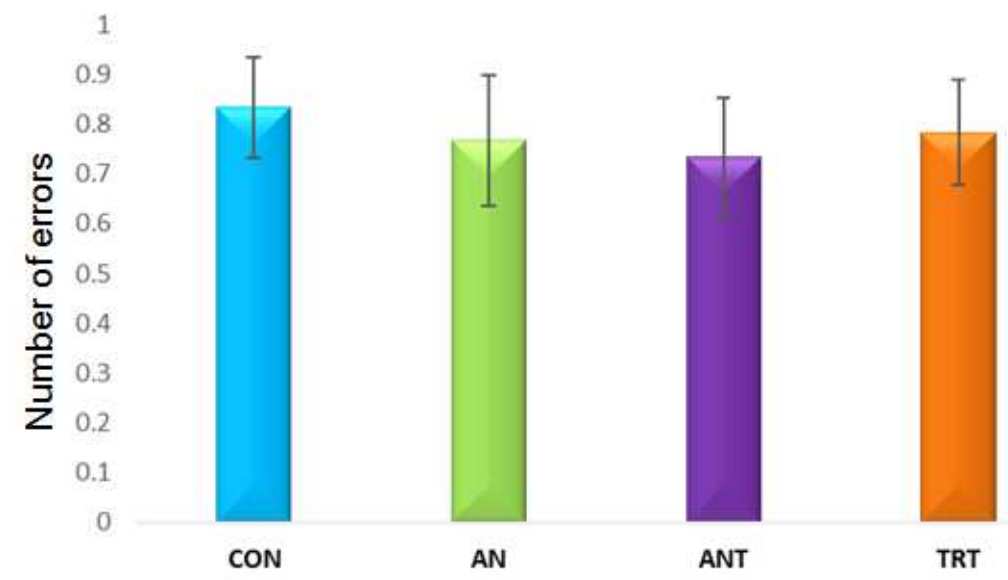

Fig. 7: Effect of Michelia champaca on working memory error in acute noise stress induced animals. Values are expressed as mean \pm SD, $\mathrm{N}=6$ 


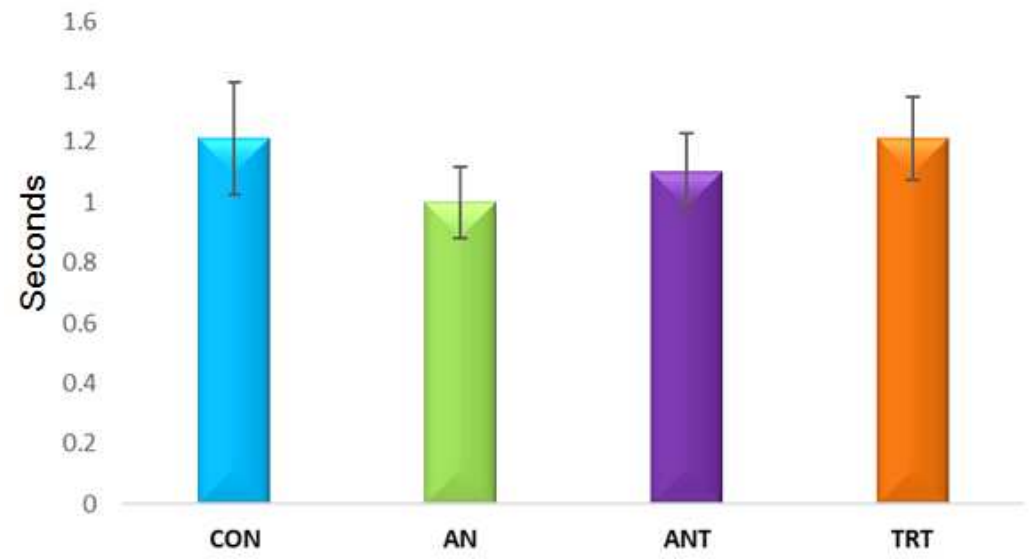

Fig. 8: Effect of Michelia time taken to complete the eight-arm maze in acute noise stress induced animals, values are expressed as mean $\pm S D, N=6$

\section{Reference and working memory error}

The data are summarized in (fig. 6 and 7) with mean \pm SD. Based on Olton's definition (1) Number of reference memory errors, i.e., each entry into a non-baited arm and (2) Number of working memory errors, i.e. re-entries into already visited baited arms were noted down along with the (3) Time taken to visit all the baited arms the scoring was done. Acute stress exposed animal's shows decreased errors in both reference and working memory error, but not significantly, animals showed better performance than the control group. Whereas in acute noise stress animal treated with $M$. champaca can able to reduce the error further when compared to other group animals.

\section{Total time taken to complete the eight-arm radial maze (EAM)}

The data are summarized in (fig. 8) were expressed with mean \pm SD. The time taken to complete the eight-arm radial maze were decreased in both acute stress and acute stress animal treated with M. champaca, but there is no significance. Whereas the performance of acute noise stress and acute noise stress animals treated with $M$. champaca were increased in all the tasks observed when compared to control group. So, M. champaca extract was found to be beneficial in memory enhancing.

\section{DISCUSSION}

Stress is a global menace fortified by the advancement of industrialization and elicited by a variety of factors, viz., and the environmental, social or pathological phenomenon of life. Considerable evidence published in the last decade have focused on a constellation of neurochemical, biochemical, and molecular effects caused by stress in the CNS, endocrine system, and immune system [20]. In general stress-induced variations are self-limiting and adaptive until and unless events that overrule "threshold" bounds become irretrievable and pathological. HPA axis is highly responsive to stress [21]. Secretion of adrenocorticotropic hormone [ACTH] from the pituitary for increased corticosterone from cortical cells to combat stress [22].

Glucocorticoid hormones can enter the brain and bind to two intracellular types of adrenal steroid receptors [23]. Glucocorticoid receptors (GRs) have a low affinity for corticosterone and become conquered during stress and at the circadian peak when, elevated circulating levels of glucocorticoids. In contrast, mineralocorticoid receptors (MRs) have a greater affinity for corticosterone and are virtually saturated under basal conditions [24]. Thus, it is likely that glucocorticoid effects on memory consolidation are due to activation of GRs. These results evidently support that GRs are selectively engaged in regulating glucocorticoid effects on memory consolidation.

An important concept that has been put forward is that glucocorticoids can both promote and inhibit the neural substrates and behavioural outputs of many aspects of cognition and emotion. Prior work has shown that the hippocampus is subject to biphasic effects of stress and glucocorticoids on synaptic plasticity and memory [25], which is complemented by demonstration of the biphasic effects on contextual fear conditioning [26]. Object recognition memory that involves hippocampal, as well as prefrontal cortical function, also shows a biphasic effect of glucocorticoids [27]. The acute stress-induced enrichment of prefrontal cortex (PFC) glutamatergic transmission directly influences the activity of PFC circuits and consequently working memory performance. The shortterm upsurge in plasma corticosterone level immediately after stress exposure was beneficial for the stressed rats to promote adaptation and survival [28], which are the characteristics of a "eustress spectrum". Schwabe et al. demonstrate that stressors and corticosterone can operate as a switch among memory systems in mice. A stressor is essential to activate the switch from one memory system to another. Stress in rats brings about transient activation of the HPA axis, as measured by increased plasma corticosterone level and other correlates of adrenal activation which prepare the organism for threatened homeostasis [29] important biochemical changes in plasma under stressful conditions i.e. elevated corticosterone is necessary to maintain the energy balance [30]. In the present study, acute stress exposure resulted in elevated plasma corticosterone. This substantial rise in the level of corticosterone after acute stress exposure is due to the novelty of the stressor. Whereas pretreatment with $M$. champaca effectively reduced the acute stress-induced elevation in the levels of plasma corticosterone. This normalizing effect on plasma corticosterone is one of the possible reasons for its adaptogenic property. Because adaptogenic agents could possess the normalizing action irrespective of the direction of forgoing pathological changes. Most studies exploring glucocorticoid effects on learning and memory have incriminated the hippocampus as the key target structure. Recent findings specify that glucocorticoid effects on memory retrieval also necessitate noradrenergic activation and basolateral complex of the amygdala [BLA] activation. BLA lesions and noradrenergic blockade prevent glucocorticoid-induced memory consolidation enhancement as well as glucocorticoid effects on memory retrieval impairment. Thus, the findings suggest that the BLA is a key structure in a memorymodulatory system that regulates stress and glucocorticoid effects on both memory consolidation and memory retrieval. Thus, during low-arousing conditions, the brain is in a state that allows for recall of information, but that does not allow for strong memory consolidation. During a stressful experience, the release of stress hormones and neurotransmitters may activate the BLA, switching the brain into a memory consolidation state, allowing for strong consolidation of this event, but consequently, and simultaneously compromising memory retrieval. Nevertheless, the modulatory effects do not hinge on BLA activation as glucocorticoid infusions into the BLA enhance memory consolidation. Therefore, it is likely that a dynamic interplay between the BLA and other brain regions, including the hippocampus and the prefrontal cortex, coordinates the antagonizing stress effects on memory consolidation and memory retrieval [31]. 
The studies on central neurotransmitter mechanisms in stress have mainly been pertaining to biogenic amines. Central cholinergic system has not been adequately explored for its involvement in stress despite its key role in the regulation of several central functions such as learning and memory. There are a few studies, which implicate cholinergic mechanism in stress. Acetylcholine [ACh] concentration in the brain of mice was reported to get altered according to the kind of stress applied [32]. Acute and repeated stress has also been stated to have marked effects on the AChE activity of numerous brain nuclei, chronic noise stress and chronic unpredictable stress alters the ACh level in the discrete regions of the brain has been reported $[49,50]$. Immobilization stress could affect the dynamics of ACh. Stress-induced changes in the hippocampal cholinergic system are more prominent in inbred Wistar-Kyoto rats which are behaviorally more reactive to stress than Brown-Norway rats [33]. Das et al. recently showed that acute immobilization stress affects brain AChE activity and cognition in adult mice [34].

These findings do suggest changes in the basal level activity of ACh in the brain after stress. However, in those studies, correlation of the biochemical changes in the cholinergic system with behavioral responses was not attempted. The fact that ACh is the most important neurotransmitter implicated in cognition [35] and the possibility that stress may influence cognitive activity [36] prompted us to investigate the status of AChE activity (in brain discrete regions) and cognitive responses in rats subjected to acute stress.

Acute stress elicits a transient upsurge in the amounts released of the neurotransmitter acetylcholine and a phase of enhanced neuronal excitability. Inhibitors of acetyl cholinesterase also endorse improved electrical brain activity, presumably by increasing the survival of acetylcholine at the synapse. Daniela Kaufe et al. [37] stated that there is similar bidirectional modulation of genes that regulate acetylcholine genes that regulate acetylcholine availability after stress and blockade of acetyl cholinesterase. These calciumdependent changes in gene expression coincide with phases of rapid enhancement and delayed depression of neuronal excitability. Both phases are mediated by muscarinic acetylcholine receptors.

Victoria et al. [38] stated that there was a decrease in AChE activity in the discrete regions of the brain of rats exposed to acute stress. Same results were observed in the present study, acute noise stress significantly decreases the AChE level. Whereas noise stress animal treated with a methanolic extract of $M$. champaca significantly reduced brain AChE activity in all the four regions studied as compared to the stress group. This suggests that the memory enhancing effect of $M$. champaca might be due to inhibition of AChE, leading to increasing in brain levels of acetylcholine. Cognitive dysfunction has been exposed to be linked with impaired cholinergic transmission and the facilitation of central cholinergic transmission resultant in improved memory. The methanolic extract of $M$. champaca showed memory enhancing activity in rat probably by inhibiting brain acetylcholinesterase activity. The AChE enzyme is described to occur in different molecular isoforms [39]. In addition, there is a differential localization of these isoforms in neuronal cells. The two major isoforms are globular monomer (G1) protein and a globular tetramer of the same monomer subunit (G4). The G1 isoform is reported to be present in the soluble cytoplasm of the neuronal cells whereas the G4 isoform is predominantly a membrane-bound enzyme [40]. The decrease in AChE activity in the acute stress group can thus be well accounted for by the decrease in the G4 isoform of AChE. Some workers have also demonstrated that the cholinergic system is altered due to stress. Gilad et al. [33] studied the cholinergic changes in the hippocampus of inbred Wistar-Kyoto rats that are behaviorally more reactive to stress than Brown-Norway rats. The immobilization stress, acute and chronic, caused a decrease in the accumulation of choline and an increase inquinuclidinylbenzilate [QNB] binding as part of an adaptive process. Finkelstein et al. [41] investigated the dynamics of cholinergic synaptic mechanisms in female rats subjected to acute and chronic immobilization stress. They observed rapid activation of presynaptic hippocampal cholinergic terminals by acute stressful stimuli expressed by an upsurge in choline uptake and newly synthesized ACh release. The septo hippocampal cholinergic system was proposed as an integral part of the adaptive response to stress.
In the present study, an adaptive process suggested by Finkelstein et al. [41] has also been seen in AChE activity. On first exposure to acute stress, a significant decrease in AChE activity was seen. Fatranska et al. [42] reported activation of the cholinergic system in rat brain areas, mainly in the hippocampus and hypothalamus, under certain stressful conditions. A significant decrease of AChE concentration in these areas was found following cold stress for 1 or $24 \mathrm{~h}$. The cholinergic neuronal loss in the hippocampal area is the major feature of Alzheimer's disease and to enhance central cholinergic activity by use of anticholinesterase, at present, is the mainstay of the pharmacotherapy of senile dementia of Alzheimer type $[43,44]$. There are reports that cognitive functions may be affected adversely, particularly in elderly subjects, due to stress [45]. In this study, eight-arm radial maze test was employed to assess the memory. It is pertinent to mention here that in the present study the eight-arm radial maze was conducted after stress which showed memory of the acutely stressed rat was not altered significantly. The results suggest that acutely stressed rats showed better cognitive activity than control animals. Stress group treated with $M$. champaca also showed increased performance this might be due to the presence of memory enhancing compounds like mianserine, resveratrol, and epicatechin in the methanolic extract of $M$. champaca [15] long-term potentiation (LTP) and primed burst (PB) potentiation are elicited by hippocampal stimulation and are believed to contribute to learning and memory. Diamond et al. [46], found an inverted $U$ relationship between circulating corticosterone and PB potentiation. Pavilides and his colleagues have found a similar relationship between corticosterone and LTP [47]. Thus, it is possible that the better performance on the radial arm maze of rats who have been stressed may involve CORT dependent enhancements of LTP or primed burst. Associative and nonassociative learning is facilitated by short-term stress [48]. Stress may facilitate the acquisition of the procedural aspect of the maze, reference memory, or facilitate short-term memory, working memory. Since stressed rats showed enhanced performance this result suggests that memory was enhanced.

This observation can be explained very well by the changes seen in AChE activity in these groups. It appears that a decrease in the G4 isoform in the hippocampal region during learning may be responsible to maintain cognitive function by enhancing the cholinergic activity. The low AChE activity in the acute stress group may upsurge cholinergic activity by raising the level of ACh leading to enhanced cognitive function.

\section{CONCLUSION}

We can concluded from this study that acute stress alter the corticosterone and AChE level whereas it didn't produce significant changes in the memory behavior analysis, so it improves memory functions and further, treatment with $M$. champaca in acute noise stress group and $M$. champaca treated alone group also showed the enhancement of memory in adult rats by suppressing brain AChE activity thereby improving the memory in the acute stress model, this is possible due to presence of rich phytochemical constituents (mianserine, resveratrol, and epicatechin)in $M$. champaca which can emerge as a therapeutic agent useful in treating memory impairments induced by noise stress. Further molecular studies are warranted to elucidate exact mechanism of action of $M$. champaca and its active principle on memory, promoting action in other animals, and also in human subjects, who are living in the noisy environment.

\section{AUTHORS CONTRIBUTIONS}

The corresponding author has designed the work and critical revision of the manuscript. The first author carried out the behavioral assessment and paper writing and second author helped to Carrie out the biochemical assays.

\section{CONFLICTS OF INTERESTS}

Authors declare that we have no conflict of interest.

\section{REFERENCES}

1. De kloet ER, Joels M, Holsboer F. Stress and the brain: from adaptation to disease. Nat Rev Neurosci 2005;6:463-75. 
2. Herman JP, Ostrander MM, Mueller NK, Figueiredo H. Limbic system mechanisms of stress regulation: hypothalamopituitary-adrenocortical axis. Prog Neuropsychopharmacol Biol Psych 2005;29:1201-13.

3. McEwen BS. Protective and damaging effects of stress mediators. N Engl J Med 1998;338:171-9.

4. McEwen BS. Physiology and neurobiology of stress and adaptation: central role of the brain. Physiol Rev 2007;87:873-4.

5. Shors TJ, Weiss C, Thompson RF. Stress-induced facilitation of classical conditioning. Science 1992;257:537-9.

6. Joels M, Pu Z, Wiegert 0, Oitzl MS, Krugers HJ. Learning under stress: how does it work? Trends Cognit Sci 2006;10:152-8.

7. McEwen BS. Stress and hippocampal plasticity. Annu Rev Neurosci 1999;22:105-2.

8. Liston C, Miller MM, Goldwater DS, Radley JJ, Rocher AB, Hof $\mathrm{PR}$, et al. Stress-induced alterations in prefrontal cortical dendritic morphology predict selective impairments in perceptual attentional set-shifting. J Neurosci 2006;26:7870-4.

9. Lupien SJ, Fiocco A, Wan N, Maheu F, Lord C, Schramek T, et al. Stress hormone and human memory function across the lifespan. Psychoneuroendocrinoligy 2005;30:225-2.

10. Shors TJ. Stressful experience and learning across the lifespan. Annu Rev Psychol 2006;57:55-5.

11. Melly S Oitzl, Holger M Reichardt, Marian Joels, Ronald de Kloet E. Point mutation in the mouse glucocorticoid receptor preventing DNA binding impairs spatial memory. Proc Natl Acad Sci 2001;98:12790-5.

12. Edwin Jarald E, Joshi SB, Jain DC. Antidiabetic activity of flower buds of Michelia champaca Linn. Indian J Pharmacol 2008;40:256-60.

13. Vimala R, Nagarajan S, Alam M, Susan T, Joy S. Antiinflammatory and antipyretic activity of Michelia champaca Linn., Ixora brachiata Roxb and Rhynchosia cana (Willd.) DC flower extract. Indian J Exp Biol 1997;35:1310-4.

14. Wei1 LS, Wee W, Siong JY, Syamsumir DF. Characterization of antimicrobial, antioxidant, anticancer property and chemical composition of Michelia champaca seed and flower extracts. J Pharm Sci 2011;4:19-4

15. Malathi S, Ravindran Rajan. Free radical scavenging activity, TLC, HPTLC and GCMS analysis of dry flower of Michelia champaca Linn. World J Pharm Res 2015;112:1576-602.

16. Samson J, Sheela Devi R, Ravindran R, Senthilvelan M. Effect of noise stress on free radical scavenging enzymes in brain. Environ Toxicol Pharmacol 2005;20:142-8.

17. Singh DK, Verma R. Spectrophotometric determination of corticosteroids and its application in pharmaceutical formulation. Iran J Parmacol Ther 2008;7:61-5.

18. Ellman GL, Courtney KD, Andres V Jr, Feather-Stone RM. A new and rapid colorimetric determination of acetylcholinesterase activity. Biochem Pharmacol 1961;7:88-95.

19. Olton DS. Mazes, maps, and memory. Am Psychol 1979;34:58396.

20. Aloe L, Alleva E, Fiore M. Stress and nerve growth factor findings in animal models and humans. Pharmacol Biochem Behav 2002;73:159-66.

21. Makara GB, Haller J. Non-genomic effects of glucocorticoids in the neural system. Evidence, mechanisms and implications. Prog Neurobiol 2001;65:367-90.

22. Walker C, Perrin M, Vale W, Rivier C. Ontogeny of the stress response in the rats: role of the pituitary and the hypothalamus. Endocrinology 1986;118:1445-51.

23. De Kloet ER. Brain corticosteroid receptor balance and homeostatic control. Frontiers Neuroendocrinol 1991;12:95-64.

24. Reul JMHM, de Kloet ER. Two receptor systems for corticosterone in the rat brain: microdistribution and differential occupation. Endocrinology 1985;117:2505-12.

25. Joels M. Corticosteroid effects in the brain: U-shape it. Trends Pharmacol Sci 2006;27:244-50.

26. Pugh CR, Tremblay D, Fleshner M, Rudy JW. Aselective role for corticosterone in contextual-fear conditioning. Behav Neurosci 1997;111:503-11.
27. Okuda S, Roozendaal B, McGaugh JL. Glucocorticoid effects on object recognition memory require training-associated emotional arousal. Proc Natl Acad Sci 2004;101:853-8.

28. Teague CR, Dhabhar FS, Barton RH, Beckwith-Hall B, Powell J, Cobain $\mathrm{M}$, et al. Metabonomic studies on the physiological effects of acute and chronic psychological stress in spraguedawley rats. J Proteome Res 2007;6:2080-93.

29. Vernikos J, Dallman MF, Bonner C, Katzen A, Shinsako J. Pituitary adrenal function in rats chronically exposed to cold. Endocrinology 1982;110:413-20.

30. Rai D, Bhatia G, Palit G, Pal R, Singh S, Singh HK. Adaptogenic effect of Bacopa monniera. Pharmcol Biochem Behaviour 2003a;75:823-30.

31. Benno Roozendaal. Stress and memory: opposing effects of glucocorticoids on memory consolidation and memory retrieval. Neurobiol Learn Mem 2002;78:578-95.

32. Fatranska M, Budai D, Oprsalova Z, Kvetnansky R. Acetylcholine and its enzymes in some brain areas of the rat under stress. Brain Res 1987;424:109-14.

33. Gilad GM, Rabey JM, Shekman L. Strain-dependent and stressinduced changes in rat's hippocampal cholinergic system. Brain Res 1983;267:171-4.

34. Das A, Kapoor K, Sayeepriyadarshini AT, Dikshit M, Palit G, Nath C. Immobilization stress-induced changes in acetylcholinesterase activity and cognitive function in mice. Pharmacol Res 2000;42:211-6.

35. Blockland A. Acetylcholine: a neurotransmitter for learning and memory? Brain Res Rev 1996;21:285-300.

36. Janowsky DS, Risch SC, Ziegler M. Central acetylcholine in stress and affective disorders. Clin Neuropharmacol 1984;7:958-9.

37. Daniela Kaufer, Alon Friedman, Shlomo Seidman, Hermona Soreq. Acute stress facilitates long-lasting changes in cholinergic gene expression. Nature 1998;393:373-7.

38. Victorialuine, Carlos Martinez, Miriam Villegas, Ana Marfa Magarilqost, Bruce S. Mcewen. Physiol Behavior 1996;59:27-32.

39. Adamson ED. Acetylcholinestrase in mouse, erythrocytes and muscles. J Neurobiochem 1977;8:605-54.

40. Massoulie J, Pezzementi I, Bon S, Krejci E, Vallette FM. The molecular and cellular biology of cholinesterases. Prog Neurobiol 1993;41:31-91.

41. Finkelstein Y, Koffler B, Rabey JM, Gilad GM. Dynamics of cholinergic synaptic mechanisms in rat hippocampus after stress. Brain Res 1985;343:314-9.

42. Fatranska M, Budai D, Oprsalova Z, Kvetnansky R. Acetylcholine and its enzymes in some brain areas of the rat under stress. Brain Res 1987;424:109-14.

43. Enz A, Amstutz R, Boddeke H, Gmelin G, Malanowski J. Brain selective inhibition of acetylcholinesterase: a novel approach to therapy for Alzheimer's disease. Prog Brain Res 1993;98:431-8.

44. Siddiqui MF, Levey AI. Cholinergic therapies in Alzheimer's disease. Drugs Future 1999;24:417-44.

45. Janowsky DS, Risch SC, Ziegler M. Central acetylcholine in stress and affective disorders. Clin Neuropharmacol 1984;7:958-9.

46. Diamond DM, Bennet MC, Fleshner M, Rose GM. Inverted U relationship between the level of peripheral corticosterone and the magnitude of hippocampal primed burst potentiation. Hippocampus 1992;2:421-30.

47. Pavlides C, Watanabe Y, Magarinos AM, McEwen BS. Opposing roles of Type I and Type II adrenal steroid receptors in hippocampal long-term potentiation. Neuroscience 1995;68:387-94.

48. Servatius RJ, Shors TJ. Exposure to inescapable stress persistently facilitates associative andnon-associative leafing in rats. Behav Neurosci 1994;108:1101-6.

49. Malathi S, Vidyashree HM, Ravindran Rajan. Restoration of memory and acetylcholinesterase activity by Michelia champaca in chronically noise-stressed wistar albino rats. Asian J Pharm Clin Res 2016;9:210-4.

50. Vidyashree HM, Malathi S, Ravindran R. Impaired object recognition memory and acetylcholinesterase activity in animal model of post-traumatic stress disorder-restored by Eclipta alba Linn. a dietary herb. Asian J Pharm Clin Res 2016;3:117-21. 